Case Report

Joumal of Epilepsy Research pISSN 2233-6249 / eISSN 2233-6257

Received October 6, 2020

Revised November 27, 2020

Accepted December 4, 2020

Corresponding author:

Jagarlapudi M. K. Murthy, MD, DM

CARE Institute of Neurosciences, CARE

Hospitals, Banjara Hills, Hyderabad 500 034,

India

Tel. +91-40-61656565

Fax. +91-40-23332124

E-mail; Jmkmurthy49@gmail.com

\title{
Juvenile Myoclonic Epilepsy: Myoclonic Status Epilepticus without Coma - Report of Three Cases
}

\author{
Jagarlapudi M. K. Murthy, MD, DM \\ CARE Institute of Neurosciences, CARE Hospitals, Banjara Hills, India
}

\begin{abstract}
Status epilepticus (SE) is rare in juvenile myoclonic epilepsy (JME). This report presents three patients with myoclonic status epilepticus (MSE). MSE is defined as prolonged period of myoclonic jerks that are correlated with epileptiform discharges on electroencephalogram. The precipitating factors among the three patients were: introduction of carbamazepine in case1, missing the dose in case2, and introduction of oxcarbazepine in case3. Of the three patients, one patient was a misdiagnosed case of JME. In him the diagnosis of JME was established after 35 years when he developed MSE with the addition of oxcarbazepine to the antiseizure medication (ASM) which he was taking. Detailed review of the history revealed that he used to get occasional myoclonic jerks with deprived sleep and stress. This patient illustrates that the diagnosis of JME can be missed or delayed if history of myoclonic jerks is not elicited, particularly in patents with pubertal onset epilepsy. The other lesson is that possibility of JME should be considered in patients with drug resistant epilepsy (pseudo-drug resistance). (2020;10:92-95)
\end{abstract}

Key words: Juvenile myoclonic epilepsy, Misdiagnosis, Myoclonic status epilepticus, Oxcarbazepine

\section{Introduction}

Juvenile myoclonic epilepsy (JME) is a clinically heterogenous, generalized epilepsy syndrome with peri-pubertal onset. Myoclonic seizure is the defining seizure type of the syndrome and other seizure types include generalized tonic-clonic seizures (GTCS) and absences. Myoclonic jerks and GTCS typically occur on awakening. Photosensitivity, eye closure sensitivity, orofacial reflex myoclonia, and praxis induction are the typical epileptic traits of JME. The diagnostic electroencephalogram (EEG) findings include normal background activity with generalized 3-6 Hz spike-waves with frontal predominance. Treatment response to valproate (VPA) is generally good. ' Status epilepticus (SE) is rarely reported in patients with JME. In a study of 133 patients with JME, only five (3.8\%) were diagnosed with SE. ${ }^{2}$ The most frequently reported SE subtypes are myoclonic SE (MSE) and nonconvulsive SE (NCSE) or absence SE (ASE). ${ }^{2-4}$ Very rarely it can be mixed absence-myoclonic status. ${ }^{4,5} \mathrm{MSE}$ is defined as prolonged period of myoclonic jerks that are correlated with epileptiform discharges on EEG. We report three patients with JME who developed MSE.

\section{Case Report}

In this study the diagnosis of JME was based on the criteria pro- posed by the international experts on JME. ${ }^{6}$ The clinical details of the patients are given in Table 1. The SE subtype was MSE in all the three patients and they were conscious throughout the period of SE. The time delay in the diagnosis of SE was mainly due to the time taken by the patients to arrive at emergency department from their place of domicile. Myoclonic jerks were brief, synchronous, grossly symmetric, and involved more upper limbs. In case 1 the jerks were frequent and involved both distal proximal muscle of both the upper limbs making her prone to dropping things. Case1 was on an inappropriate antiseizure medication (ASM) and carbamazepine (CBZ) when presented with MSE. The female patient was diagnosed with JME, well controlled on VPA (600 mg per day). She stopped valproate (VPA) after her marriage and had an episode of GTCS for which she was prescribed CBZ by the family physician.

Case3 was a misdiagnosed case of JME. The diagnosis of JME was established only when the male patient developed MSE with the use of oxcarbazepine (OXC). He consulted first time the physician for the new-onset GTCS at the age of 20 years and was initially put on phenobarbital and phenytoin with which he used to have GTCSs once in 1-2 months. He consulted several physicians including neurologist and was extensively investigated with 3-T magnetic resonance imaging and multiple EEGs which were all normal. He was tried on several ASM. When he consulted us, he was on phenobarbitone and 
levetiracetam. We also considered the diagnostic possibility of drug resistant epilepsy and OXC was added. He developed continuous myoclonic jerks evolving to MSE within a week of use of OXC (Fig. 1C). He stopped OXC on his own with which the severity and frequency of myoclonic jerks had come down. Detailed history revealed that he used to get occasional myoclonic jerks precipitated by deprived sleep and stress, which we failed to elicit during his first visit. He is a misdiagnosed case of JME. During his first visit we should have asked for history of myoclonic jerks as he had the onset of epilepsy at around puberty.

Ictal EEG in case1 showed frequent paroxysm of generalized poly-spikes and occasional poly-spike discharges (Fig. 1A) and some of them were associated with myoclonic jerks. In case2 ictal EEG showed paroxysms of generalized poly-spikes initially followed by 3.5 Hz spike-wave and occasional poly-spike discharges. The background activity was normal (Fig. 1B) and there here were associated myoclonic jerks. In case3 ictal EEG showed frequent transients of spike-wave and poly-spike discharges associated with (Fig. 1C). All the patients received IV midazolam $0.2 \mathrm{mg} / \mathrm{kg}$ followed by IV loading dose of VPA (40 mg/kg) and MSE was terminated. Case2 was continued on valproate. Case1 was initially put on VPA and during follow-up VPA was changed to levetiracetam as the female patient was in the reproductive age group. She was counselled about planned pregnancy. Case3 was put on VPA 1,000 mg q12h and other ASMs are slowly being withdrawn.

\section{Discussion}

The reported incidence of MSE in patients with JME had a wide range from $1.4 \%$ to $42 \%$. This wide range may be related to different methodologies and definitions used in the studies. ${ }^{3,4,7,8}$ In a retrospective study of 69 patients with JME, the estimated prevalence and

Table 1. Clinical characteristics of patients JME and myoclonicus status epilepticus

\begin{tabular}{|c|c|c|c|c|c|}
\hline Age/sex & Primary diagnosis & Precipitating factor & $\begin{array}{l}\text { Status type and } \\
\text { clinical features }\end{array}$ & EEG features & Treatment and outcome \\
\hline $\begin{array}{l}\text { Case1: } 25 \\
\text { years/female }\end{array}$ & $\begin{array}{l}\text { Diagnosed case of } \\
\text { JME and on } \\
\text { valproate } 600 \\
\text { mg, counselled } \\
\text { regarding } \\
\text { marriage and } \\
\text { pregnancy }\end{array}$ & $\begin{array}{l}\text { Stopped valproate after } \\
\text { her marriage, had an } \\
\text { episode of GTCS, local } \\
\text { physician changed } \\
\text { valproate to } \\
\text { carbamazepine }\end{array}$ & $\begin{array}{l}\text { MSE (duration 16-17 hours) } \\
\text { Conscious, no neurological } \\
\text { deficits, frequent } \\
\text { myoclonic jerks } \\
\text { predominantly distal } \\
\text { involving proximal and } \\
\text { distal muscles of upper } \\
\text { limbs, occasional dropping } \\
\text { of objects from hands }\end{array}$ & $\begin{array}{l}\text { Ictal EEG: frequent } \\
\text { paroxysmal } \\
\text { generalised } \\
\text { poly-spike and } \\
\text { occasional } \\
\text { poly-spike-wave } \\
\text { discharges, } \\
\text { almost } \\
\text { continuous 4-5 } \\
\text { Hz (Fig. 1A) }\end{array}$ & $\begin{array}{l}\text { MSE was terminated with IV } \\
\text { midazolam }(0.2 \mathrm{mg} / \mathrm{kg}) \\
\text { followed by valproate } \\
40 \mathrm{mg} / \mathrm{kg} \text { loading dose and } \\
\text { was put on valproate } 600 \\
\mathrm{mg} \text { per day. In the } \\
\text { follow-up valproate was } \\
\text { changed to levetiracetam } \\
1,000 \mathrm{mg} / \text { day and was } \\
\text { counselled regarding } \\
\text { conception and pregnancy }\end{array}$ \\
\hline $\begin{array}{l}\text { Case2: } 20 \\
\text { years/male }\end{array}$ & $\begin{array}{l}\text { JME on valproate } \\
\text { 1,000 mg/day, } \\
\text { no seizures }\end{array}$ & $\begin{array}{l}\text { Stopped valproate since } \\
\text { one month as he is } \\
\text { seizure free }\end{array}$ & $\begin{array}{l}\text { MSE (duration } 16-18 \text { hours) } \\
\text { Conscious, no neurologic } \\
\text { deficits } \\
\text { Frequent myoclonic jerks } \\
\text { mainly involving proximal } \\
\text { muscle in both upper limbs }\end{array}$ & $\begin{array}{l}\text { Ictal EEG: frequent } \\
\text { paroxysmal } \\
\text { generalized spike } \\
\text { and wave and } \\
\text { occasional } \\
\text { poly-spike and } \\
\text { wave } \\
\text { poly-spike-wave } \\
\text { discharges, 3-4 } \\
\text { Hz (Fig. 1B) }\end{array}$ & $\begin{array}{l}\text { MSE was terminated with IV } \\
\text { midazolam }(0.2 \mathrm{mg} / \mathrm{kg}) \\
\text { followed by IV valproate } \\
(40 \mathrm{mg} / \mathrm{kg}) \text { loading. He } \\
\text { was continued on } \\
\text { valproate } 500 \mathrm{mg} \mathrm{q} 12 \mathrm{~h}\end{array}$ \\
\hline $\begin{array}{l}\text { Case3: } 55 \\
\text { years/male }\end{array}$ & $\begin{array}{l}\text { Misdiagnosis of } \\
\text { JME and being } \\
\text { treated as a case } \\
\text { of drug resistant } \\
\text { epilepsy with } \\
\text { phenobarbitone } \\
\text { and } \\
\text { levetiracetam }\end{array}$ & $\begin{array}{l}\text { He visited our clinic, we } \\
\text { also considered the } \\
\text { diagnostic possibility of } \\
\text { drug resistant epilepsy } \\
\text { and oxcarbazepine was } \\
\text { added, following } \\
\text { which he developed } \\
\text { frequent myoclonic } \\
\text { jerks }\end{array}$ & $\begin{array}{l}\text { MSE (duration } 48 \text { hours) } \\
\text { Conscious, no neurologic } \\
\text { deficits, frequent jerking of } \\
\text { both the upper limbs } \\
\text { mostly proximal muscles }\end{array}$ & $\begin{array}{l}\text { Ictal EEG: frequent } \\
\text { paroxysmal } \\
\text { generalized } \\
\text { ply-spike and } \\
\text { rare spike-wave } \\
\text { discharges, } 4-5 \\
\text { Hz (Fig. 1C) }\end{array}$ & $\begin{array}{l}\text { MSE was terminated by IV } \\
\text { midazolam } 0.2 \mathrm{mg} / \mathrm{kg} \\
\text { followed by IV loading } \\
\text { dose of valproate ( } 40 \\
\mathrm{mg} / \mathrm{kg} \text { ). He was started on } \\
\text { valproate } 1,000 \mathrm{mg} \mathrm{q} 12 \mathrm{~h} \\
\text { and the other ASMs are } \\
\text { being withdrawn }\end{array}$ \\
\hline
\end{tabular}

JME, juvenile myoclonic epilepsy; EEG, electroencephalogram; GTCS, generalized tonic-clonic seizures; MSE, myoclonic status epilepticus; ASM, antiseizure medication. 

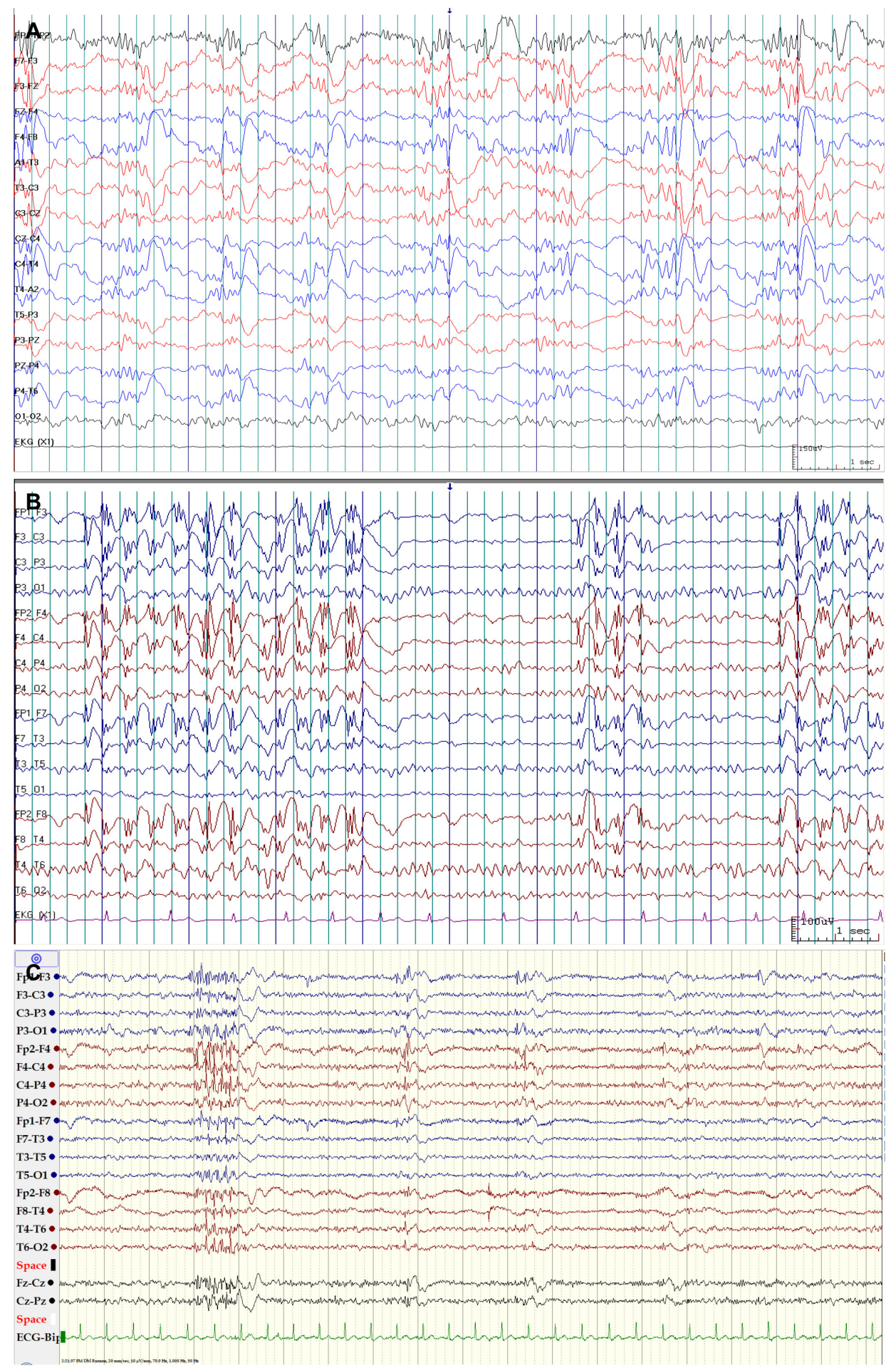

Figure 1. (A) Ictal EEG in case1. Anterior-posterior longitudinal bipolar montage showing normal background activity and frequent paroxysms of generalized symmetrical and synchronous poly-spikes and occasional poly-spike and wave discharges. Patient was fully aware during the EEG recording and having myoclonic jerks. (B) Ictal EEG in case2. Anterior posterior longitudinal bipolar montage showing normal background activity and frequent bursts of generalized, symmetrical, and synchronous 3-3.5 Hz spike-wave and poly-spike and wave discharges. Patient was aware during the EEG recording and having myoclonic jerks. (C) Ictal EEG in case3. Anterior posterior longitudinal montage showing normal background activity and frequent bursts of generalized, symmetrical, and synchronous poly-spike and spike-wave discharges. Patient was aware during the EEG recording and having myclonus. EEG, electroencephalogram. 
annual incidence of NCSE were $5.8 \%$ and $1.2 \%$, respectively. ${ }^{3}$ The new classification of SE categorizes the status into CSE and NCSE based on the presence or absence of prominent motor symptoms and the degree of impaired consciousness. MSE is categorized under convulsive SE and is further divided into MSE with coma (mixed absence myoclonic SE) and MSE without coma. NCSE or ASE is categorized under NCSE without coma, typical absence status. ${ }^{9}$ In the series reported by Larch et al., ${ }^{4}$ three patients had MSE immediately after termination of GTCS and two patients had GTCS with myoclonic absence. In our patients, MSE was the SE subtype.

The new definition of SE is conceptual, with two time points: $t_{1}$ (when a seizure is likely to be prolonged leading to continuous seizure activity) and $t_{2}$ (when a seizure may cause long-term consequences). The $t_{1}$ for ASE is considered to be 10-15 minutes and time for $t_{2}$ is uncertain. ${ }^{9}$ For MSE the data are not yet available to define the two time points. In view of these limitations, we define MSE as "continuous or intermittent bilateral myoclonic jerks with preserved awareness lasting for at least 30 minutes". In case1 and case2, the duration of statue was about 16-18 hours and in case 3 it lasted for 48 hours. A comparative study for differences between JME with SE and JME without SE observed that myoclonic jerks limited to specific body parts (one arm, face or head) were significantly more common in patients with SE. ${ }^{2}$

The common and important precipitants for SE in patients with JME are deprived sleep, inappropriate ASM, ASM noncompliance, and alcohol. ${ }^{2-5}$ The precipitant in case 1 was inappropriate ASM, in case2 ASM nonadherence, and in case3 misdiagnosis and use of inappropriate ASMs, OXC. The delay in diagnosis was due to failure to ask for myoclonic jerks, even he had new-onset GTCS around pubertal age. The correct diagnosis was made only after he developed MSE with the use of OXC. Aggravation of genetic generalized epilepsy syndromes by inappropriate ASMs has been well documented, particularly with CBZ. Precipitation of MSE and ASE by inappropriate use of CBZ in JME has rarely been reported. ${ }^{10}$ Use of OXC in JME can exacerbate myoclonic and absence seizures. ${ }^{11}$ The first report of SE in JME with the use of OXC was done by Fanella and colleagues. ${ }^{12}$ This report is probably the second patient. He is a misdiagnosed case of JME and precipitation of MSE with the use of OXC established the diagnosis of JME after 36 years of onset of epilepsy. Jeong et al. ${ }^{13}$ re- ported two patients diagnosed with JME by first-ever status epilepticus in adult life. These three patients' cases emphasizes the importance of asking for myoclonic jerks in patients with new-onset GTCS around pubertal age. GTCS is the seizure type for which most patients with JME seek medical attention for the first time.

\section{References}

1. Baykan $B$, Wolf $P$. Juvenile myoclonic epilepsy as a spectrum disorder: a focused review. Seizure 2017;49:36-41.

2. Oğuz-Akarsu E, Aydin-Özemir Z, Bebek N, Gürses C, Gökyiğit A, Baykan B. Status epilepticus in patients with juvenile myoclonic epilepsy: frequency, precipitating factors and outcome. Epilepsy Behav 2016;64(Pt A):127-32.

3. Dziewas R, Kellinghaus C, Lüdemann P. Nonconvulsion status epilepticus in patients with juvenile myoclonic epilepsy: types and frequencies. Seizure 2002;11:335-9.

4. Larch J, Unterberger I, Bauer G, Reichsoellner J, Kuchukhidze G, Trinka E. Myoclonic status epilepticus in juvenile myoclonic epilepsy. Epileptic Disord 2009;11:309-14.

5. Gélisse P, Crespel A. Mixed myoclonic-absence status epilepticus in juvenile myoclonic epilepsy. Epileptic Disord 2015;17:95-6.

6. Kasteleijn-Nolst Trenité DG, Schmitz B, Janz D, et al. Consensus on diagnosis and management of JME: from founder's observations to current trends. Epilepsy Behav 2013;28 Suppl 1:S87-90.

7. Panayiotopoulos CP, Obeid T, Tahan AR. Juvenile myoclonic epilepsy: a 5-year prospective study. Epilepsia 1994;35:285-96.

8. Asconapé J, Penry JK. Some clinical and EEG aspects of benign juvenile myoclonic epilepsy. Epilepsia 1984;25:108-14.

9. Trinka $E$, Cock $H$, Hesdorffer $D$, et al. A definition and classification of status epilepticus--report of the ILAE task force on classification of status epilepticus. Epilepsia 2015;56:1515-23.

10. Thomas P, Valton L, Genton P. Absence and myoclonic status epilepticus precipitated by antiepileptic drugs in idiopathic generalized epilepsy. Brain 2006;129(Pt 5):1281-92.

11. Gelisse P, Genton P, Kuate C, Pesenti A, Baldy-Moulinier M, Crespel A. Worsening of seizures by oxcarbazepine in juvenile idiopathic generalized epilepsies. Epilepsia 2004;45:1282-6.

12. Fanella $M$, Egeo $G$, Fattouch J, et al. Oxcarbazepine-induced myoclonic status epilepticus in juvenile myoclonic epilepsy. Epileptic Disord 2013;15:181-7.

13. Jeong HS, Moon JS, Oh ES, Kim JM. Two patients diagnosed with juvenile myoclonic epilepsy by first-ever status epilepticus in adult life. J Epilepsy Res 2011;1:32-4. 